\title{
Trap thickness and the subtrappean structures related to mode of eruption in the Deccan Plateau of India: results from magnetotellurics
}

\author{
B. P. K. Patro ${ }^{1}$ and S. V. S. Sarma ${ }^{2}$ \\ ${ }^{1}$ National Geophysical Research Institute, Hyderabad \\ ${ }^{2}$ New Nallakunta, Hyderabad \\ (Received February 16, 2006; Revised August 24, 2006; Accepted August 30, 2006; Online published March 21, 2007)
}

\begin{abstract}
Deccan trap thickness is an important parameter in understanding the eruption process of flood basalts (65 My). A magnetotelluric study was carried out in Deccan Volcanic Province (DVP) of the Indian Peninsular shield during 1998-1999. Modeling results clearly revealed variations both in the thickness of the Deccan traps and in their resistivity from the west coast to the eastern boundary of DVP. The thickness of the traps in DVP decreases from about $1.8 \mathrm{~km}$ in the west to a few hundred meters (approx. $400 \mathrm{~m}$ ) towards the east. The traps also exhibit considerable variation in resistivity, with higher resistivities (approx. 150-200 ohm-m) in the western half and lower resistivities (approx. 50-100 ohm-m) in the eastern half of DVP. Two significant fissure/fracture zones have been detected in DVP; these may have acted as conduits for the outpouring of Deccan lavas in addition to the primary structures along the west coast and the Narmada-Son lineament (NSL) zones.
\end{abstract}

Key words: Deccan traps, resistivity, magnetotellurics, fissures.

\section{Introduction}

Deccan traps, which form a vast flood basalt province in the Indian peninsula, are generally believed to have erupted at the close of the Cretaceous, some $65( \pm 4)$ mya when the Indian continent-following its separation from Madagascar-moved over the Reunion hotspot during its northward journey (Morgan, 1981; Duncan and Pyle, 1988; Allegre et al., 1999). Geochronological studies have shown that the eruption of these massive amounts of lavas occurred rapidly over a period of only 1-4 million years (Courtillot et al., 1986, 1988; Duncan and Pyle, 1988; Baksi, 1994). Other major basalt provinces similar to the Deccan are the Parana basalts of South America, the Siberian Traps of Russia, Karoo of Africa, Columbia River Basalts of North America, Caribbean Sea-floor basalts and the Ontong Java plateau in Western Pacific Ocean.

The Deccan traps occupy an area of nearly $500,000 \mathrm{~km}^{2}$, which makes this formation the second most extensive geological formation in Peninsular India, next only to the Archean igneous and metamorphic complex. The traps occupy large tracts in Saurashtra and Kutch in the west and northwest, extending to Belgaum in the south, Sarguja and Jashpur in the east and as far as Rajmahendri in the SE, covering parts of the states of Gujarat, Maharashtra, Madhya Pradesh and Karnataka. The lava flows are typically characterized by expansive, thick tabular sheets. Individual flows have been observed to extend over distances of 100 $\mathrm{km}$, as in the case of flows between Nagpur in Maharashtra and Chindwara in Madhya Pradesh. They are mostly horizontal and form flat-topped hills with step-like terraces

Copyright (c) The Society of Geomagnetism and Earth, Planetary and Space Sciences (SGEPSS); The Seismological Society of Japan; The Volcanological Society of Japan; The Geodetic Society of Japan; The Japanese Society for Planetary Sciences; TERRAPUB. that have been produced by differential weathering and erosion. The compact flows form the tops of the terraces and plateaus and have steep slopes, whereas the vesicular and amygdaloidal ones produce gentle slopes. The thickness of individual flows may vary from a few meters to as much as $40 \mathrm{~m}$. The Deccan trap column also shows significant variations in thickness.

Both the deciphering of the thickness variations of the traps and acquiring insights into the nature of the subtrappean lithology and structure constitute important data inputs that would promote an understanding of the geology, structure and tectonics of the Deccan trap region. There have been a few attempts to estimate the thickness of the traps using conventional geophysical methods, such as gravity, magnetics and seismics (Negi et al., 1983; Tiwari et al., 2001; Kaila et al., 1981a, b). While such studies have a number of limitations in terms of delineating the configuration of the trap thicknesses and the nature of the subtrappean lithology, magnetotellurics has been shown to be very effective in investigating trap-covered areas (Sarma et al., 1998; Gokarn et al., 1992; Patro et al., 2005a, b). Utilizing the natural electromagnetic signals as its source field, magnetotellurics (MT) provides a detailed electrical structure which in turn can be interpreted in terms of lithology and geological structure over a range of depths extending from very shallow levels to as much as a few tens of kilometers. The MT technique finds several applications, such as crust/mantle structure investigations, regional tectonic studies, stratigraphic mapping, geothermal and mineral exploration and the evaluation of sedimentary basins in oil prospecting. In the present study an attempt is made to determine the configuration of the Deccan trap thickness by applying this approach and studying its relation to the possible localizations and structures through which the lava 


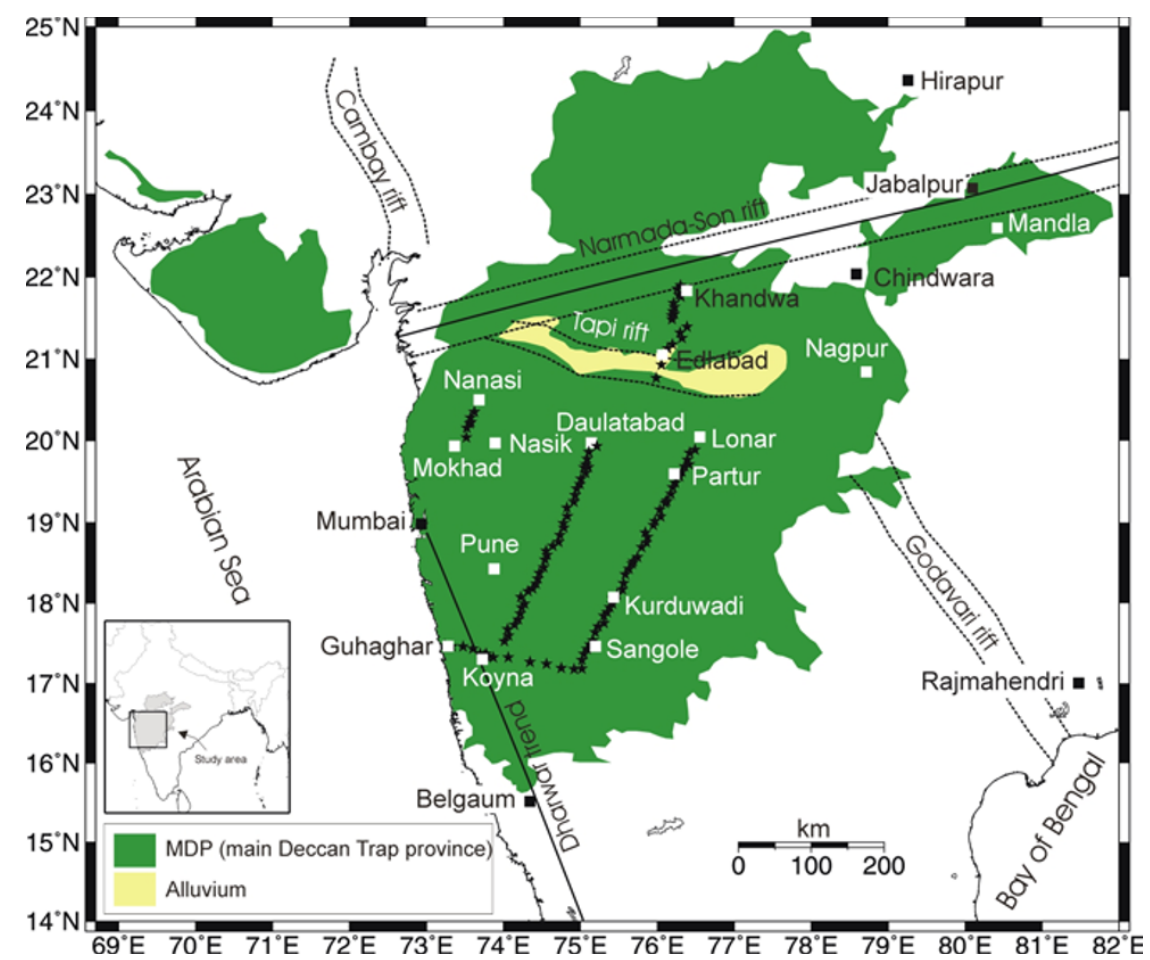

Fig. 1. Location of magnetotelluric traverses plotted over the geological map of Deccan Volcanic Province (DVP) (modified after Biswas, 1987; Peng et al., 1994).
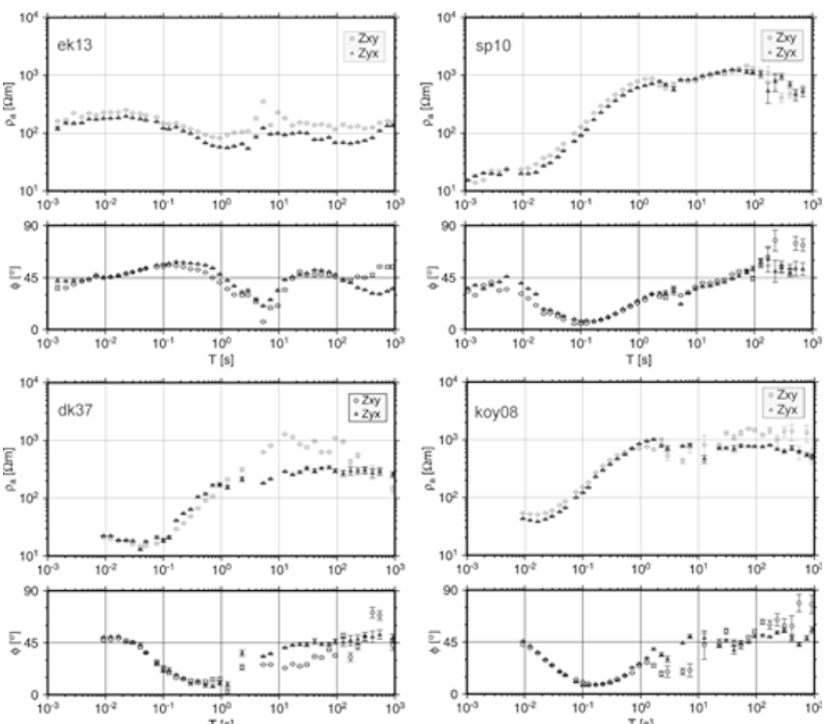

Fig. 2. Magnetotelluric transfer functions (apparent resistivity and phase) in the measured geographic north $(\mathrm{X})$ and geographic east $(\mathrm{Y})$ direction at representative sites (ek13, sp10, dk37 and koy08) in DVP.

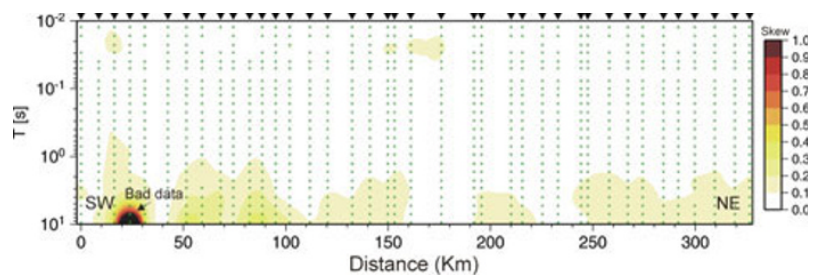

Fig. 3. Swift skew-period section along SP traverse for the high-frequency $(100-0.1 \mathrm{~Hz})$ data. Green dots indicate the data points.

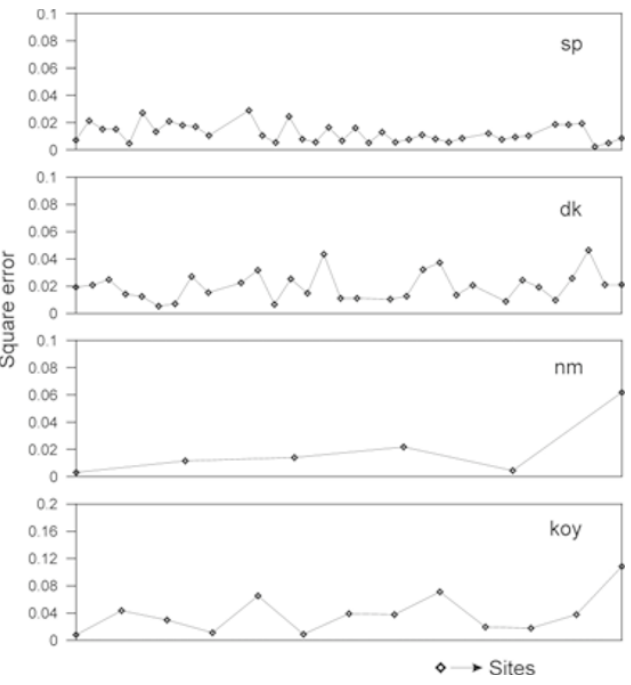

Fig. 4. Square error plots for sites along the $\mathrm{sp}, \mathrm{dk}, \mathrm{nm}$ and koy traverses for Marquardt inversion responses of effective impedances

erupted in the Deccan plateau.

\section{MT Field Investigations}

MT data acquisition entails the simultaneous measurement of orthogonal components of variations in the magnetic field and the corresponding induced electric field variations over a wide frequency range. The relationship between the magnetic and electric field variations measured at the earth's surface provides the basic information about the depth distribution of the earth's subsurface electrical conductivity in the form of complex impedance as a function of frequency. 
In the present study, we interpret the results of an analysis of wide-band (0.001-1000 s) MT data obtained from a total of 139 MT sounding sites on the Deccan Plateau that were situated along five different traverses cutting across some of the major gravity 'highs' and 'lows' in order to examine the thickness configuration and subtrappean structure. The MT traverses are (1) Guhaghar-Sangole (GS), covering the Koyna region in the southern half of Deccan Volcanic Province (DVP); (2) Daulatabad-Koyna (DK) and Sangole-Partur (SP), traversing across the DVP; (3) Edlabad-Khandwa (EK) in the Khandwa region in the northern half of DVP; (4) Nanasi-Mokhad (NM), a short traverse in the western DVP. Figure 1 shows the location map of the MT traverses, together with the surface geology.

\section{Variations in Deccan Trap thickness across the Deccan Plateau}

The MT data were acquired along the geographic north $(\mathrm{X})$ and geographic east (Y) directions. Magnetotelluric transfer functions at representative sites from different traverses (ek13, sp10, dk37 and koy08) are presented in Fig. 2. The data at short periods represent the skin depths that correspond to the top Deccan trap cover in the region. Because of the well-known stratified nature of traps exhibiting only very gentle dips $\left(<3^{\circ}\right)$, the data may be considered to represent a horizontal layered situation and hence permit a one-dimensional (1-D) modeling approach. The Swift skew presented in Fig. 3 indeed shows very small values $(<0.1)$ that are consistent with the 1-D situation. Accordingly, the Marquardt-style inversion technique was adopted to derive the layer parameters. The Marquardt inversion requires a starting model with the desired number of layers, and during the process of inversion it modifies the resistivities and thicknesses of the layers until it minimizes the root mean square (RMS) error between the model response and the observed data. The two parameters, the average impedance $Z_{a v}=\left(Z_{x y}-Z_{y x}\right) / 2$ (Berdichevsky and Dmitriev, 1976) and the effective impedance $Z_{d e t}=\left(Z_{x x} Z_{y y}-Z_{x y} Z_{y x}\right) 1 / 2$ (where $Z_{x x}, Z_{y y}$ are diagonal elements and $Z_{x y}, Z_{y x}$ are antidiagonal elements of the impedance tensor) (Ranganayaki, 1984) were used for the 1-D inversion. The MT data have been inverted for obtaining 1-D models at all sites. Estimates from both parameters agree closely with each other. In the present case the square error is generally below 0.6. Figure 4 shows the error plot for all of the sites along different traverses for the case of the Marquardt inversion of effective impedance.

The 1-D models revealed details of the Deccan trap configuration along all the traverses as well as the nature of the shallow subsurface section. The thickness of the trap along the 325-km-long SP traverse (Fig. 5(a)) varies from 200 to $700 \mathrm{~m}$, with a maximum thickness of about $700 \mathrm{~m}$ in the middle of the traverse. In a similar manner, the thickness of the trap along the DK traverse (Fig. 5(b)) varies from 400 to $900 \mathrm{~m}$, with the thickest layer found at the southern end of the traverse. The NM traverse (Fig. 5(c)), however, which is at the western boundary of the DVP, shows a significant increase in trap thickness-based on modeling results - with the thicknesses varying from 1.3 to $1.8 \mathrm{~km}$. The thickness of the trap increases along the GS traverse (Fig. 5(d)) from the east to the west, with a thickness of approximately 500 $\mathrm{m}$ at the eastern-most end and about $1.3 \mathrm{~km}$ near the west coast.

The EK traverse passes through an important tectonic zone known as the Narmada-Son Lineament (NSL) zone. The geology and tectonics of the NSL zone are characterized by a series of deep crustal-scale structural features. The skew (Swift and Bahr's) parameter along this profile has elevated values at certain locations, indicating the degree of complexity. Consequently, we applied the 2-D approach to the high-frequency MT data. The high-frequency data (1000-1 Hz) along the EK traverse was inverted using the rapid relaxation inversion (RRI) algorithm of Smith and Booker (1991). Based on the strike analysis (for details, see Patro et al., 2005b), the data were rotated to $\mathrm{N} 75^{\circ} \mathrm{E}$ and assigned the E-polarization (TE mode) to the rotated xy component and the B-polarization (TM mode) to the rotated $y x$ component. Both TE and TM mode data were used in the inversion. The model obtained after inversion is presented in Fig. 5(e). The rms misfit for TEmag, TEphase, TMmag and TMphase are 6.329, 7.224, 5.036 and 8.035, respectively. The trap thickness along the EK traverse in the NSL zone derived from the model (Fig. 5(e)) ranges from 0.8 to $1.2 \mathrm{~km}$.

The thickness of the trap in the DVP thus decreases significantly from west to east almost by a factor of 3 . While the thickness of the traps is large $(1.3-1.8 \mathrm{~km})$ along the NM traverse (the western-most traverse), it decreases to about 200-700 $\mathrm{m}$ along the SP traverse, indicating a general thinning of the traps from west to east in the DVP. Figure 6 presents a fence diagram showing these results. The observed variations in trap thickness may be partly attributed to the nature of pre-trappean topography and to the distance from the source regions. However, it is interesting to note that the trap thickness and the present ground elevations (Fig. 9) are generally directly correlated.

In addition to the trap thickness profiles, we have also attempted to retrieve a broad regional picture of the Deccan trap configuration, which is presented as a contour map in Fig. 7, by integrating inputs from the MT models on the Deccan trap thickness estimates in this region. The contour map clearly brings out the primary feature, namely the thickening of the traps along the west coast and the NSL zone, which are the two main source regions of Deccan traps, bordering the DVP on its west and north. Similarly, the thinning of the traps with increasing distance from these source regions, particularly from west to east, can be readily seen on the map.

\section{Resistivity Variation in the Traps}

In addition to the presence of thickness variations along the individual traverses, the trap resistivity also changes from west to east, with higher resistivity values (150-300 ohm-m) estimated for the NM traverse in the west and lower ones (approx. $50 \mathrm{ohm}-\mathrm{m}$ ) for the SP traverse. The thicker trap column was found to be associated with higher resistivities and the thinner one with relatively lower resistivities. It may be recalled that each of the trap layers generally consists of massive as well as vesicular portions. The vesicular portions, being porous and permeable, may contain fluids 


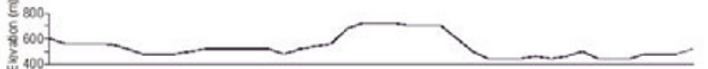

Partur

a)

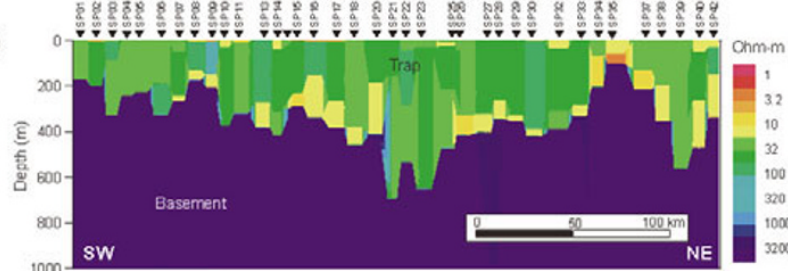

Koyna

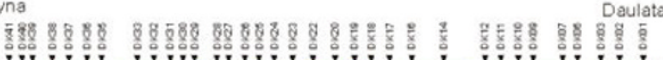
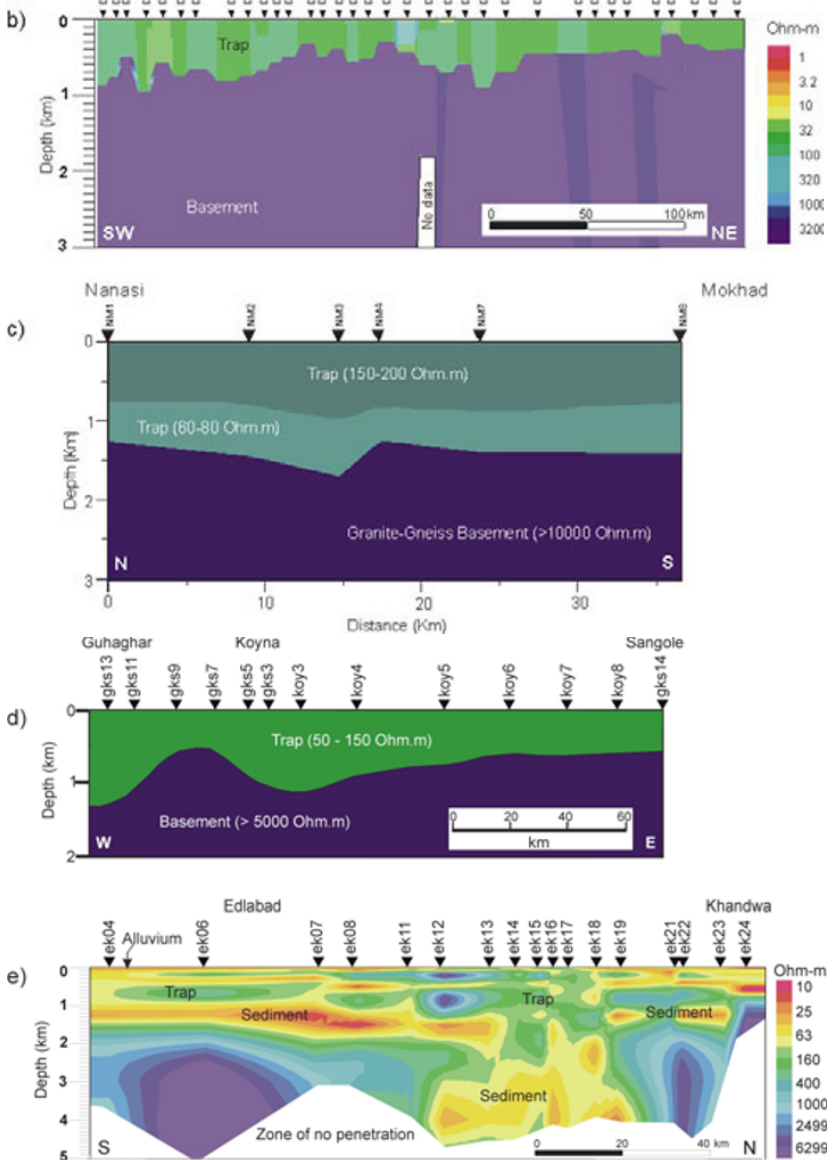

Fig. 5. Shallow geoelectric sections derived from one-dimensional modeling of effective impedances along (a) Sangole-Partur (b) Daulatabad-Koyna (c) Nanasi-Mokhad (d) Guhaghar-Sangole traverses and (e) geoelectric section along Edlabad-Khandwa traverse, based on two-dimensional rapid relaxation inversion. The elevation profile is also shown for the profile Sangole-Partur.

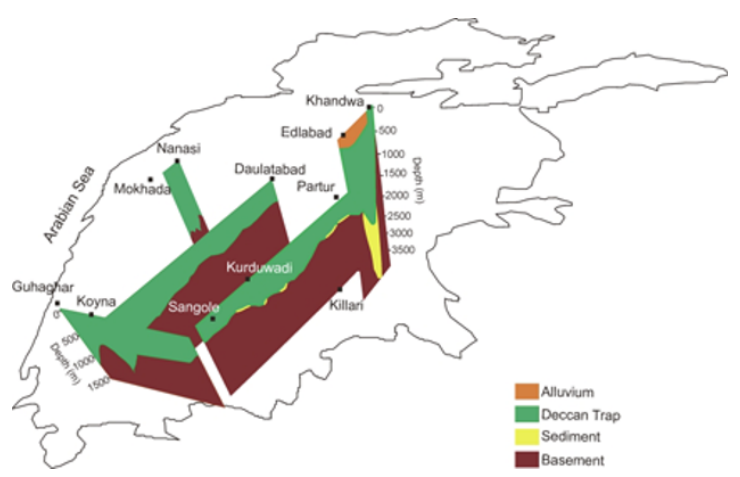

Fig. 6. Fence diagram showing the variation of trap thickness along all the five traverses across the DVP.

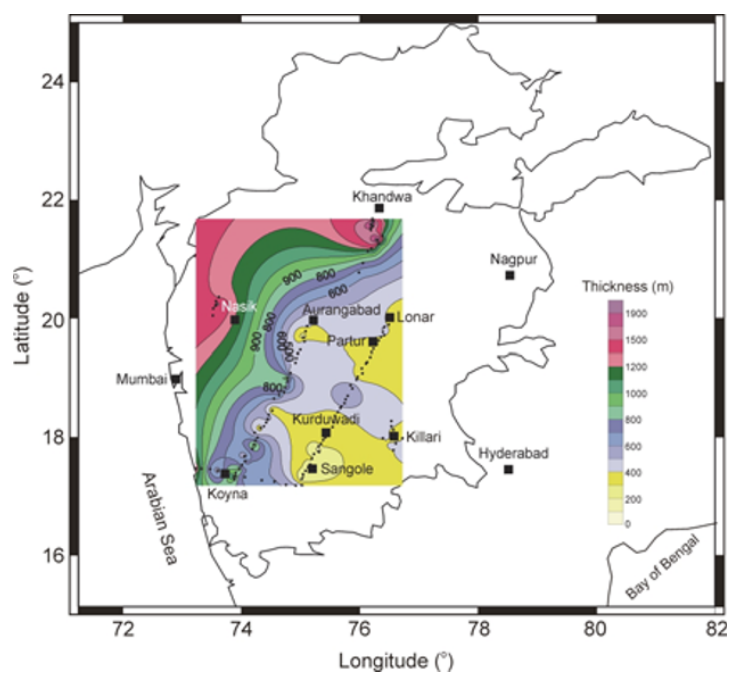

Fig. 7. Contour map of Deccan trap thickness based on the inputs from the present MT models along different traverses in the DVP. This map provides a broad regional picture of the Deccan trap configuration in the DVP. Black dots indicate the location of MT sites.

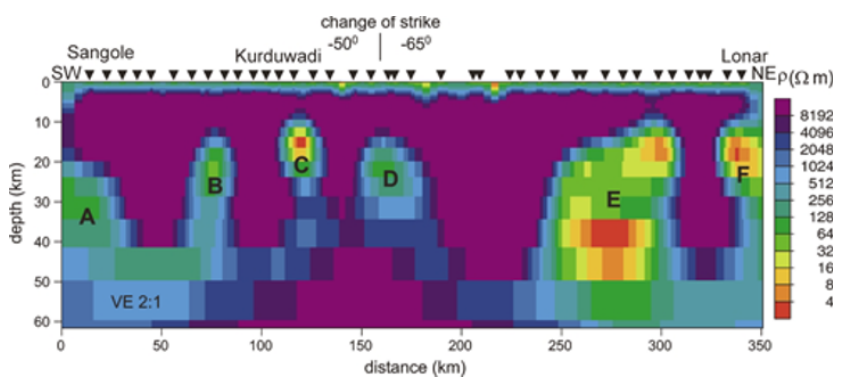

Fig. 8. Subsurface geo-electric section along the Sangole-Partur traverse derived from the two-dimensional inversion of MT data (after Patro et al., 2005a).

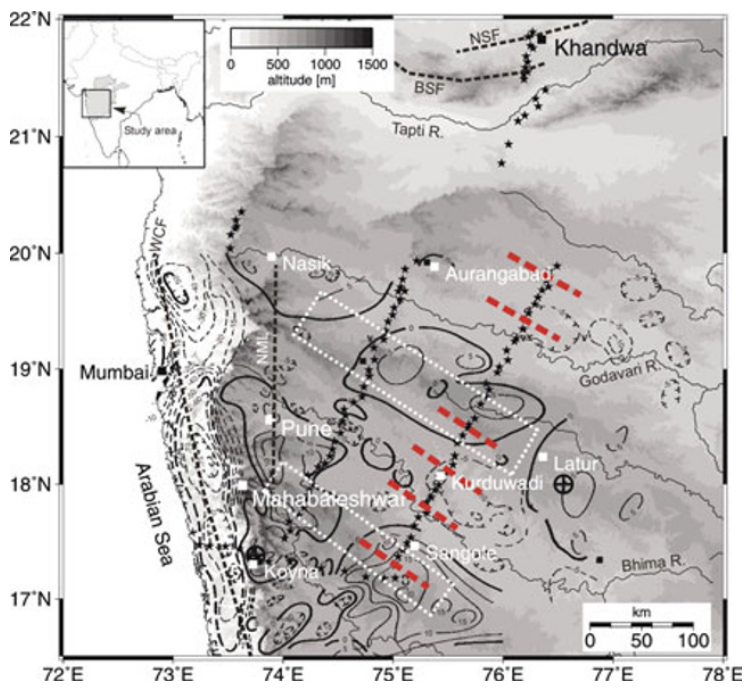

Fig. 9. MT site locations (marked as star) plotted over the topography in the DVP. In the background, zero free air gravity anomaly (Subbarao, 2002) contours are shown. The west coast fault (WCF) is redrawn from Biswas (1982). The Nasik-Mahabaleshwar line (NML) of volcanic eruption is redrawn from Mahadevan and Subbarao (1999). The Narmada South Fault (NSF) and Barwani-Sukta Fault (BSF) are redrawn from Crumansonata (1995). White dotted rectangles mark the zones of high elevation and high gravity; the thick broken lines indicate the locations of deeper conductive zones from MT studies (Patro et al., 2005a) 
that reduce the electrical resistivity, while the massive portions of the trap, which are compact, are generally highly resistive. The traps also exhibit weathering, which again lowers the resistivities, and the vesicular portions in particular are vulnerable to weathering. On the other hand, it is also possible that vesicles in the vesicular traps are sometimes filled with secondary minerals like silica, which gives the contents an amygdoloidal texture; as such, these portions may show up as resistive layers similar to the massive traps. It may be recalled that the traps in the western region of DVP, belonging to the Kalsubai group, which is the dominant and the oldest of the Deccan traps, are characterized by amygdoloidal basalts. It may be inferred that the increased thicknesses, which are generally associated with a thicker column of massive and compact traps, together with the characteristic amygdoloidal texture of the western region of DVP may be responsible for the higher resistivities exhibited by traps along the NM traverse in the western region. On the other hand, the thinning and surface weathering and, to some extent, the presence of clay layers and intra-trappeans might contribute to the lowering of trap resistivities observed along the SP traverse, as compared to that along the NM traverse. The results from the Columbia River flood Basalts of Washington state (USA) show that the resistivity of basalt is $300 \mathrm{ohm} . \mathrm{m}$ (Smith et al., 1999).

\section{The Subtrappean Sediments}

The normal stratified basaltic cover comprising several trap layers appears to be almost a horizontal layer with resistivities ranging from 50 to $200 \mathrm{ohm}-\mathrm{m}$ and shows moderate variations in thickness. This overlies a high resistive basement, with the occasional intervening low resistive layer that corresponds to the Mesozoic sediments between the trap and the basement. The results do not indicate any significant amount of subtrappean conductive sediments in the DVP along the SP, DK, NM and GS traverses, with the exception of thin patches at a few places along the SP traverse. For example, in the southern half of the traverse between SP13 and SP18 and in the northern half in the region between SP34 and SP37, these conductive sediments occur as thin $(300 \mathrm{~m})$ conductive layers (approx. 10-20 ohm-m) (Fig. 5(a)). However, along the EdlabadKhandwa traverse at the northern boundary of DVP, a conductive (approx. 15-25 ohm-m) layer below the traps is delineated, which is interpreted to be subtrappean Gondwana sediments. While the thickness of these subtrappean sediments varies along the traverse, one impressive feature of these sediments is a sudden thickening of the layer (approx. $2 \mathrm{~km}$ ) below a thick trap layer (approx. $2 \mathrm{~km}$ ) in the middle of the traverse, indicating a subtrappean Gondwana sedimentary basin (Fig. 5(e)).

\section{Mode of Eruption of Deccan Volcanics: The Fissures and Fractures}

The Deccan trap lavas are believed to be continental basalts that erupted through tensional fissures. The west coast fault zone, particularly between Bombay and Kambhat, and the Narmada-Son lineament zone are considered to be the two major source regions from which the Deccan lavas are believed to have poured out through tensional fractures (see West, 1999). These lavas flowed great distances towards the east and south to form a vast sheet of volcanic cover, commonly known as DVP or, more specifically, the South Eastern Platform Block (SEPB) (Mahadevan and Subbarao, 1999). The results of the present MT studies on this aspect provide valuable clues for furthering our understanding of this problem. The decreasing thickness of the traps from west to east (Fig. 7) is in line with this hypothesis. While the variations in thickness from west to east amount to a factor of three, the same is not true for the N-S direction where it appears to be rather smaller, presumably indicating the lesser extent of the outflow of Deccan lavas from the northern source region towards south relative to that from west to east. This may be due to less favorable pre-trappean topographic conditions for the dispersal of the lava flows or to the sources in the NSL zone not being as significant as those in the west coast fault zone.

\section{Crustal Conductors and the NW-SE Trending Gravity Highs: Evidence for Fissure Zones in the DVP}

While Bhimas and Kaladgi Proterozoic basins occupy the southern fringe of the DVP, peninsular granite-gneissic rocks occupy the eastern fringe. The granite-gneissic rocks along with their major structural grain/elements, with the general strike varying from N-S to NW-SE, are believed to continue north-westwards and form the basement for the Deccan traps. It is also noteworthy the DVP is characterized by dominant NW-SE trending linear Bouguer Gravity "highs" and "lows" which have been interpreted in different ways, such as as subsidences and uplifts (Kailasam, 1979) and as Rift valleys (Krishna Brahmam and Negi, 1973), although direct evidence for such subsurface rift models is not provided by any available geophysical constraints, such as deep seismic sounding studies and magnetotellurics (Kaila et al., 1979, 1981a, b; Gokarn et al., 1992; Patro et al., 2005a).

At least six major NW-SE trending vertical conductive features that cut across the DVP (see Fig. 8) have already been identified and subsequently interpreted to represent fault/fracture zones, some fluid-enriched and some presumably hosting mafic intrusive rocks along the fracture zones (Patro et al., 2005a). The zero free air gravity anomaly map for the DVP region shown in Fig. 9 (Subbarao, 2002) clearly depicts two NW-SE trending gravity "high" features-one in the northern half of the DVP extending from around Latur towards Nasik and another in the southern half extending from Sangole towards the west and northwest, splaying into two branches: one trending almost E-W and extending towards Koyna and the other extending in a northwesterly direction towards Pune. These gravity features closely follow the linear topographic "highs" which cut across the DVP and which are also shown to be marked by thick trap cover (Fig. 9). In addition, the gravity features, the topographic highs and the thickened trap cover locales also spatially coincide with the well-defined crustal scale vertical linear conductive features discussed above, as shown in Fig. 9. Based on the integration of these results, the linear features characterized by high-density, high-conductivity, high-elevation, thickened trap cover are interpreted to be representing mega 
fissure/fracture zones that might have acted as secondary conduits/source regions for the outpouring of Deccan lavas in the DVP, in addition to the two primary source fracture zones in the Cambay and the NSL regions. That such secondary fissure/fracture zones might exist in the Deccan trap areas has also been suggested on geological grounds (see Ray, 1967). Similarly, the identification of localized areas of thick trap cover-for example, as observed near Mandla in the North or near Corochi east of Koyna in the south - the presence of dikes at the eastern fringe of DVP and the occurrence of significant interbedded pyroclastic layers in the DVP region are some of the indirect indicators that point towards the possible existence of isolated eruptive sources in DVP (Subbarao et al., 1995; Mahadevan and Subbarao, 1999). While the two linear geophysical anomalous features in the DVP represent two major fissure/fracture zones that might have acted as secondary source regions for the outpouring of Deccan lavas, the intervening linear gravity "lows" that cut across the DVP in a NW-SE direction - for example, the Kurudwadi featuremay reflect additional fracture zones associated with more acidic type of igneous/volcanic rocks of relatively low density (see Tiwari et al., 2001).

The linear gravity anomalies in peninsular India have been interpreted to represent block uplifts and subsidences due to vertical tectonics (Kailasam, 1979). The major secondary fracture zones identified here may represent the linear weak zones along which such vertical uplifts and subsidences of crustal blocks might have occurred. These fracture/fault zones representing secondary sources/conduits for the Deccan lavas also assume significance from the viewpoint of seismotectonics of the DVP region.

\section{The Nasik Mahabaleshwar Line (NML) Zone}

Geological mapping studies suggest a domal structure near Nasik, called the Nasik dome, which is considered to be a primary volcanic structure related to a volcanic shield (Subbarao et al., 1994; Sen 2001). Older flows are centered around Nasik and the region southwards is occupied mainly by the younger Wai group of flows as far south as Belgaum (Subbarao and Hooper, 1988; Mitchel and Widdowson, 1991). The Nasik dome together with the Mahabaleshwar anticline constitutes a major tectonic line popularly known as the Nasik-Mahabaleswar line (NML) (Fig. 9). Linked to the eastern fringe of the Kutch-Cambay rift zone, the NML is considered to be its eastern collar (Beane et al., 1986; Bodas et al., 1988). The NML, which is characterized by a thick pile of lava flows with the presence of abundant compound flows, is considered to represent an important structural zone containing several major eruptive centers of Deccan volcanics. The Wai group of flows, which erupted out along the NML, flowed towards the east. Since these flows traveled great distances eastwards, it is generally suggested that the NML and the region west of it was elevated much above the DVP platform level, presumably due to thermal doming (Radhakrishna, 1991, 1993), before the eruption of the younger Wai flows. A part of the NML zone is also characterized by a N-S trending zero free air gravity "high", indicating the presence of a major fracture zone and hosting significant thick column of high-ensity Deccan trap source lavas.

However, the presence of major eruptive centers, as envisaged along the NML, should characterize the subsurface by significant conductive subsurface roots penetrating deep into the crustal column, as observed in MT electrical images of other similar, known structural features, such as the Girnar complex in Saurashtra (Sarma et al., 1998). This could form the basis for the identification of unknown hidden volcanic plugs/vents/major eruptive centers in the Deccan trap areas. The geoeletric model for the NanasiMokhad traverse in the Nasik region indicates a rather a simpler subsurface picture in which there is a thick (1.3$1.8 \mathrm{~km}$ ) volcanic Deccan trap column lying directly over a highly resistive medium, with resistivities amounting to as much as several thousands of ohm-m, apparently representing a granite-gneissic basement. In order to delineate the presence of such volcanic vents/plugs, more detailed studies are indeed necessary and should cover a much larger area in this important region, including the region west of NML.

\section{Conclusions}

1. The thickness of the traps in Deccan Volcanic Province decreases from about $1.8 \mathrm{~km}$ in the west on the NM traverse to a few hundred meters (approx. $400 \mathrm{~m}$ ) towards the east on the SP traverse.

2 . The traps also exhibit considerable variation in resistivity, with higher resistivities (approx. 150-200 ohm-m) on the western half and lower resistivities (approx. 50-100 ohm-m) on the eastern half of the DVP.

3. No major column of subtrappean mesozoic sediments exists along the SP, DK, GS and NM traverses in DVP, with the exception of a few thin patches along the SP traverse. However, along the Edlabad-Khandwa traverse in the NSL zone, a thick column of sediments (as much as $2.0 \mathrm{~km}$ thick) constituting a subtrappean Gondwana sedimentary basin is detected and delineated.

4. The subtrappean upper crustal section in the DVP is highly resistive ( $>10,000 \mathrm{ohm}-\mathrm{m})$, indicating that it is predominantly representative of a granitic-gneissic crust, inferred to be continuation of the Dharwarian crust.

5. Anomalous regions hosting hidden volcanic sources, whether they be volcanic cones or fissures, may indeed be picked up through MT imaging coupled with gravity studies in basalt-covered regions. Two such major fissure zones have been detected in DVP which showed coincident linear features characterized by "highs" in electrical conductivity, gravity, elevation and trap thickness.

Acknowledgments. This study was funded by the Department of Science and Technology (DST), Government of India. We thank Dr. V. P. Dimri, the Director of NGRI for his constant encouragement and permission to publish this work. Thanks are due to Dr. T. Harinarayana for his interest and cooperation. The authors would like to thank Dr. T. Hashimoto and the anonymous reviewers for their valuable comments that helped to improve the manuscript.

\section{References}

Allegre, C. J., J. L. Birck, Capmas, F. and V. Courtillot, Age of the Deccan Traps using ${ }^{187} \mathrm{Re}-{ }^{187}$ Os systematics, Earth Planet. Sci. Lett., 170, $197-$ 204, 1999. 
Baksi, A. K., Geochronological studies on whole-rock basalts, Deccan traps, India: evaluation of the timing of volcanism relative to the K-T boundary, Earth Planet. Sci. Lett., 121, 43-56, 1994.

Beane, J. E., C. A. Turner, P. R. Hooper, K. V. Subbarao, and J. N. Walsh, Stratigraphy, composition and form of Deccan Basalts, Western Ghats, India. Bull. Volcanol., 48, 61-83, 1986.

Berdichevsky, M. N. and V. I. Dmitriev, Basic principles of interpretation of magnetotelluric sounding curves, in Geoelectric and Geothermal Studies, pp. 165-221, edited by A. Adam, KAPG Geophysics Monographs, Akademiai Kiado, Budapest, 1976.

Biswas, S. K., Rift basins in western margin of India and their hydrocarbon prospects with special reference to Kutch basin, Am. Assoc. Petr. Geol. Bull., 66, 1497-1513, 1982.

Biswas, S. K., Regional tectonic framework, structure and evolution of the western marginal basins of India, Tectonophysics, 135, 307-327, 1987.

Bodas, M. S., S. F. R. Khadri, and K. V. Subbarao, Stratigraphy of the Jawahar and Igatpuri formations, Western Deccan Province, in Deccan Flood Basalts, edited by K. V. Subbarao, Mem. Geol. Soc. India, 10, 235-252, 1988.

Crumansonata, Geoscientific studies of the Son-Narmada-Tapti Lineament zone, Geological Society of India, Special Publication 10, 371, 1995.

Courtillot, V., J. Besse, D. Vandamme, T. Montigny, J. J. Jaeger, and H. Cappetta, Deccan flood basalts at the Cretaceous/Tertiary boundary?, Earth Planet. Sci. Lett., 80, 361-374, 1986.

Courtillot, V., G. Féraud, H. Maluski, D. Vandamme, M. G. Moreau, and J. Besse, Deccan flood basalts and the Cretaceous/Tertiary boundary, Nature, 333, 843-846, 1988.

Duncan, R. A. and D. G. Pyle, Raid eruption of the Deccan Traps at the Cretaceous/Tertiary boundary, Nature, 333, 841-843, 1988.

Gokarn, S. G., C. K. Rao, B. P. Singh, and P. N. Nayak,. Magnetotelluric studies across the Kurduwadi gravity feature, Phys. Earth Planet. Int., 72, 58-67, 1992.

Kaila, K. L., K. Roy Chowdhury, P. R. Reddy, V. G. Krishna, Hari Narain, S. I. Subbotin, V. B. Sollogub, A. V. Chekunov, G. E. Kharetchko, M. A. Lazarenko, and T. V. Ilchenko, Crustal structure along Kavali-Udipi profile in the Indian Peninsular Shield from deep seismic soundings, $J$. Geol. Soc. India, 10, 307-333, 1979.

Kaila, K. L., P. R. Reddy, M. M. Dixit, and M. A. Lazrenko, Deep crustal structure at Koyna, Maharashtra indicated by Deep Seismic Soundings, J. Geol. Soc. India, 22, 1-16, 1981a.

Kaila, K. L., P. R. K. Murty, V. K. Rao, and G. Kharetchko, Crustal structure from deep seismic sounding along the KOYII (Kelsi-Loni) profile in the Deccan trap area, India, Tectonophysics, 73, 365-384, 1981 b.

Kailasam, L. N., Plateau uplift in Peninsular India, Tectonophysics, 61, 243-269, 1979.

Krishna Brahmam, N. and J. G. Negi, Rift valleys beneath the Deccan trap (India), Geophys. Res. Bull., 11, 207-237, 1973.

Mahadevan, T. M. and K. V. Subbarao, Seismicity of the Deccan Volcanic Province-An evaluation of some endogenous factors, Mem. Geol. Soc. India, 43, 453-484, 1999.

Mitchell, C. and M. Widdowson, A geological map of the southern Deccan traps, India and its structural implications, J. Geol. Soc. London, 148, 495-505, 1991.

Morgan, W. J., Hotspot tracks and the opening of the Atlantic and Indian
Oceans, in The Sea, edited by C. Emiliani, Vol. 7, pp. 443-487, John Wiley, New York, 1981.

Negi, J. G., P. K. Agrawal, and K. N. N. Rao, Three-dimensional model of the Koyna area of Maharashtra state (India) based on the spectral analysis of aeromagnetic data, Geophysics, 48, 964-974, 1983.

Patro, B. P. K., H. Brasse, S. V. S. Sarma, and T. Harinarayana, Electrical structure of the crust below the Deccan Flood Basalts (India), inferred from magnetotelluric soundings, Geophys. J. Int., 163, 931-943, 2005a.

Patro, B. P. K., T. Harinarayana, R. S. Sastry, M. Rao, C. Manoj, K. Naganjaneyulu, and S. V. S. Sarma, Electrical imaging of NarmadaSon Lineament Zone, Central India from magnetotellurics, Phys. Earth Planet. Inter., 148, 215-232, 2005 b.

Peng, Z, X., J. Mahoney, P. Hooper, C. Harris, and J. Beane, A role for lower continental crust in flood basalt genesis? Isotopic and incompatible element study of the lower six formations of the western Deccan Traps, Geochim. Cosmochim. Acta, 58, 267-288.

Radhakrishna, B. P., An excursion into the past-"The Deccan volcanic episode", Curr. Sci., 61, Nos 9/10, 641-647, 1991.

Radhakrishna, B. P., Neogene uplift and geomorphic rejuvenation of the Indian peninsula, Curr. Sci., 64, Nos. 11/12, 787-793, 1993.

Ranganayaki, R. P., An interpretive analysis of magnetotelluric data, Geophysics, 49, 1730-1748, 1984.

Ray, S., Petrologic evolution of the Deccan traps, Sci. Cult., 33, 252-256, 1967.

Sarma, S. V. S. et al., Magnetotellurics studies, (in) Integrated Geophysical Studies For Hydrocarbon Exploration Saurashtra, India, NGRI Technical Report No: NGRI-98-EXP-237, pp. 181-262, 1998.

Sen, G., Generation of Deccan Trap magmas, Proc. Indian Acta. Sci (Earth Planet. Sci.), 110, 409-431, 2001.

Smith, T., M. Hoversten, E. Gasperikova, and F. Morrison, Sharp boundary inversion of 2D magnetotelluric data, Geophys. Prospect., 47, 469-486, 1999.

Subbarao, K. V., C. Mitchell, and M. Widdowson, Latur continental earthquake from the southeastern Deccan Basalt Province, India. Abstract. IUGG Meeting 1995. Section of SW7 Intracontinental Earthquakes, 1995.

Subbarao, K. V. and P. R. Hooper, Reconnaissance map of the Deccan basalt group in Western Ghats, India, in Deccan Flood Basalts, edited by K. V. Subbarao, Mem. Geol. Soc. India, No. 10, 1988.

Subbarao, K. V., D. Chandrasekharam, P. Navaneethakrishnan, and P. R. Hooper, Stratigraphy and structure of parts of the central Deccan Basalt province: Eruptive models, in Volcanism, edited by K. V. Subbarao, Wiley Eastern Ltd., pp. 321-332, 1994.

Subbarao, D. V., Zero-free air-based gravity anomaly (preliminary) map of South India-A refined and redefined Bouguer map, Curr. Sci., 82, No. 11, 2002.

Tiwari, V. M., M. B. S. Vyaghraswara Rao, and D. C. Mishra, Density inhomogeneties beneath Deccan volcanic province, India, as derived from gravity data, J. Geodyn., 31, 1-17, 2001.

West, W. D., The Deccan Trap and Other Flood Eruptions-a comparative study, Mem. Geol. Soc. India, 43, 129-144, 1999.

B. P. K. Patro (e-mail: patrobpk@rediffmail.com) and S. V. S. Sarma 